\title{
Impacts of Human-Wildlife Conflict in Developing Countries
}

\author{
${ }^{*}$ GEMEDA, DO; ${ }^{2}$ MELES, SK \\ ${ }^{1}$ Jimma University College of Agriculture and Veterinary Medicine, Department of Natural Resources Management, Jimma, \\ Ethiopia. \\ *Corresponding Author Email: dessalegn.obsi@ju.edu.et;dasoobsi@gmail.com \\ Telephone: +251-917-85-23-22 \\ ${ }^{2}$ Wolkite University, College of Natural and Computational Science, Department of Biology, Wolkite, Ethiopia. \\ E-mail:kirosseyoum@yahoo.com
}

\begin{abstract}
This paper is aimed to investigate the driving forces for human-wildlife conflict in developing countries in order to develop conservation strategies. Human-wildlife conflict has been occurring whenever an action by human or wildlife in a particular habitat. This problem has been in existence as long as wild animals and people shared the same resources. The expansion of human population into or near to areas inhabited by wildlife and modification of the natural environments for agricultural activities escalate human-wildlife conflict. The problem of human-wildlife conflict is frequently reported in developing countries in the form of crop raiding, livestock depredation, predation on managed wild animal species or killing of people. Crop damage is the most prevalent form of human-wildlife conflict across African continent. Hippopotamuses, baboons, rodents, grivet monkey, squirrels, porcupines, pigs, deer, elephants, spotted hyenas, leopards, and lions are some of the reported wildlife that affects community livelihoods in developing countries. Crop loss and livestock depredation by wildlife is contributing the problem of food insecurity and poverty in developing countries. Human wildlife conflict hinders the conservation of animals in the natural habitats and poses the greatest challenges to the persistence and survival of wildlife. Therefore, all concerned stakeholders will work to minimize the existing humanwildlife conflict through developing human-wildlife conflict management techniques.
\end{abstract}

\section{DOI: https://dx.doi.org/10.4314/jasem.v22i8.14}

Copyright: Copyright $\odot 2018$ Gemeda and Meles. This is an open access article distributed under the Creative Commons Attribution License (CCL), which permits unrestricted use, distribution, and reproduction in any medium, provided the original work is properly cited.

Dates: Received: 13May 2018; Revised: 27July: 2018; Accepted: 28 August 2018

Keywords: Crop loss,crop-raiding, developing countries, human-wildlife, livestock depredation

Human-wildlife conflicts (HWC) occurred when human beings take negative actions on wildlife and vice-versa. Conover (2002) defined the term HWC as occurring whenever an action by human or wildlife has an adverse effect on each other. Such conflicts have been recorded thought the world in terrestrial, aquatic, and aerial environments and have involved a wide variety of animal taxa (Torres et al.,2018). Primates and other wild animals are increasingly affected by habitat destructions and encroachments by human beings for various economic activities (Fourie et al., 2015). When contradictory situation appears between people and wildlife in the form of crop raiding, livestock depredation, killing of people leads to HWC(Woodroffe et al., 2005).The issue of HWC is not a recent phenomenon. Human wildlife conflict has old as old as human civilization, yet currently the phenomenon poses a serious environmental challenge and has been escalated over the past few decades (Anand and Radhakrishna, 2017). Human-wildlife conflicts have been in existence as long as wild animals and people shared the same resources. Sharing and completion for limited resources will leads to HWC. Crop-riding by wild animals is a common problem all over the world (Fenta, 2014;
Gandiwa et al., 2013; Gandiwa et al., 2012; Kate, 2012; Gusset et al.,(2009). This conflict is worsening in areas where humans and wild animal's requirements overlap (Gandiwa et al., 2012). The conflict is occurring everywhere in the world. Although, the problem of HWC is exist everywhere, the situation is more severe for Africa continent where majority of the people depends on agriculture, which accelerates the conversion of wild habitat to agricultural fields (Kate, 2012). Crop damage is the most prevalent form of HWC across African continent (FAO, 2009). The expansion of human population into or near to areas inhabited by wildlife and modification of the natural environments for agricultural or other economic activities escalate HWC (Hockings and Humle, 2009; Knight (2000).

Natural forests are being cleared and the primates are facing great challenges. HWC mitigation is crucial for conservation of wildlife (Ogra and Badola, 2008). Residential and commercial development, agriculture and aquaculture expansions into forest areas are the main challenges that affect the life of wildlife. Understanding drivers of HWC is a prerequisite for developing effective and cost efficient conservation 
strategies. This paper is aimed to investigate the driving forces for human-primate conflict and to support policy makers and conservationist.

\section{MATERIALS AND METHODS}

Several published scientific documents and reports on human-wildlife conflict were reviewed on developing countries. Various databases, Google scholar, TEEAL and Google web were investigated to assess relevant information on human-wildlife conflict. Several keywords like human-wildlife conflict, crop-raiding and livestock depredation were used to be found in the keyword, title or abstract of the published documents. Finally, the most appropriate articles or documents were selected and used for this review paper.

What are the Causes of Human-Wildlife Conflict (HWC)?: Habitat Destructions and Fragmentation: It isobvious that human beings are over-exploiting forests for development activities, such as road constructions, collecting timber and non-timber forest products which can reduce forest coverage and later on they can forced the primate species and other wild animals to move out of their range for resource completion and survival. The transformation of forests, savannah and other ecosystems into agrarian areas or urban centers as a consequence of the increasing demand for land, food, energy and raw materials, has led to a dramatic decrease in wildlife habitats (FAO, 2009).

Human wildlife conflict have become more frequent and severe over recent decades as a result of human population growth, extension of transport routes and expansion of agricultural and industrial activities which together have led to increased human encroachment on previously wild and uninhabited areas (FAO, 2009).

Global civilization and rapid population growth contributes for the destructions wildlife habitat that leads to competition for survival. As human population expands and natural habitats shrink, people and animals increasingly come into conflict over living space and people lose their crops, livestock, property and sometimes their lives (Mishra et al. 2014).

Habitat loss and anthropogenic altering of forest structures pose a threat to forest-dependent primate species (Singh et al.,2018). Kansky and Knight (2014) conclude that increasing pressures on biodiversity will increase the frequency and magnitude of HWC events. Habitat simplification will decrease ecosystem vitality and services, increasing wildlife-human conflict and insecurities (Everard et al., 2017). Habitat fragmentation specifically forest is inevitably a critical driver of human-wildlife conflicts, although the extent of effects varies depending on species specific habitat requirements (Acharya et al., 2017). For instance, Hippopotamuses can cause substantial damages while feeding at night while Baboons and vervet monkeys are raiding food crops (FAO, 2009).

Impacts of Huma-Wildlife Conflicts: Human-wildlife conflicts occurred in the form of crop damage, livestock predation to animal attacks on people (Mishra et al., 2014; Ogra and Badola (2008). There are different situation which enhance the frequency of HWC. For instance, direct threat to human life, destructions of property, direct competition for forage between domestic livestock and wild herbivores and damage of agricultural crops by wild animals are among the major driving forces for HWC (Datta-Roy et al., 2009).

Crop Raiding: Crop raiding is one of the most common conflicts between people and wildlife in developing countries.Majority of Africa human population depends on land for various economic activities with high proportions on Agriculture coupled with the presence of many species of large mammal's leads to HWC (Hill, 1998). Study conducted by Marchal and Hill (2009) in Indonesia on the topic entitles as 'Primate Crop-raiding: A study of local perceptions in four villages in North Sumatra, Indonesia' reported that about $94.9 \%$ of the respondents claimed that wildlife is causing damages to cultivars; most important were squirrels, porcupines, pigs, deer, elephants and primates. Huge amounts of crops were lost by wildlife in different countries across Africa countries.For instance, on study conducted in Nigeria shows that out of 853 bags of $50 \mathrm{~kg}$ crops expected from a planting season, 379 bags were perceived to be destroyed by primates while farmers harvested $474(55.6 \%)$ as leftover (Eniang et al., 2011). This problem is enhanced when the wildlife unable to get their diet from the natural habitat and compute for daily life. Degradation of wildlife habitats and expansions of agricultural lands due to rapid human population growth probably forces wildlife into crop raiding. Rapid human population growth enhanced human encroachment on previously wild and uninhabited areas for agricultural and other economic activities particularly in African countries. Another study conducted by Fenta (2014) in southern Ethiopia on the sample size of 30 respondents, $63.3 \%$ claimed that they encountered with snatching of food items by Baboons and Monkeys and $20 \%$ of the respondents indicated that they experienced destruction of property, $10 \%$ encounter human disruption when they were sleeping and $10 \%$ of the 
respondents reported that they encounter threats with noctumal carnivores such as spotted hyenas when walking in the night. As demonstrated in (Table 1) the issues of HWC is not a single factor, but it is the combination property grab, destruction, disruption and threats.

Crop raiding affects not only loss of crops but also it affects the life of future generation by decreasing the percentage of school enrolments. When the problem is severe the family forced their children to protect the crop from wildlife. Study conducted by Hill (2005) on Uganda reported that Baboons cause considerable damage to some farms. Similar to Baboons, elephants are also causing crop damages in the country. Seven years later, another study by Mackenzie and Ahabyona (2012) on the topic entitled as 'Elephants in the garden; financial and social costs of crop raiding' reported that many children drop their education to stay at home and protect crops from damage. Elephant is considered as one of the crop-raiding wildlife in some African countries like Gabon, Ghana, Malawi, Uganda and Zimbabwe (Table 2). In 1996, about $21 \%$ of crop was lost only in Uganda (Hoare, 1999 cited in FAO (2009). The percentage of crop lost by elephant in Zimbabwe and Mozambique is also significant that can affect food security and escalate human-elephant conflicts. Human-wildlife conflict is a growing global problem that adversely affects agricultural productions and people livelihoods. Crop-riding by wild animals is one of the major causes for HWC (Regmi et al., 2013; Dickman, 2010; Hill (2005).
Livestock depredation: The most common causes of these conflicts are the direct attack of predators on human and domestic animals and degradation of crops (Torres et al., 2018). Large carnivores like lions, spotted hyenas and leopards were reported to attack cattle, donkey's goats and sheep in Tanzania (Kissui, 2008). Other studies in Ethiopia by Yihune et al, (2009) indicated that spotted hyena caused the most pronounced problems and the local communities' loss their oxen, cows, donkeys, mules and horses by spotted hyena. Carnivores are attacking domestic livestock due to declining number of herbivorous in the wild due to prolonged droughts and habitat degradation (Marchant, 2010 cited Mwamidi et al., (2012). In Kenya, lions circumvent fences by going through the warthog holes hence crossing over to unprotected areas and killing livestock like goats and sheep (Mwamidi et al., 2012).

Killings of wildlife: Because of limited access to cash and lack of compensated for crop losses, the local communities of Ethiopia is more suffered by crop damaged by wild animals. Study conducted by (Mojo et al., 2014) in Checha district of Gurage Zones in Ethiopia, shows that grivet monkey is one of the major wild animals that frequently damage crops. Cropraiding undermines food security and tolerance of wildlife within neighboring human communities (Hill and Wallace, 2012). The inability to mitigate cropraiding and absence of composition for crop losses lead to killing of animals (Regmi et al., 2013). One review article in India by Anand and Radhakrishna (2017) on the topic investigating trends in humanwildlife conflict: is conflict escalation real or imagined? Clearly shows that the number of species involved in HWC doubled from 38 in 1976-1995 to 76 during 1996-2015 (Figure 1).

Table 1: HWC around Wondo Genet College of Natural Resources, Ethiopia (Adopted from Fenta, 2014).

\begin{tabular}{lll}
\hline Types of Conflict & Frequency & Percentage \\
\hline Snatch food items from Kitchen, tables and people's hands & 20 & 63.3 \\
Destruction of property & 6 & 20 \\
Human disruption & 3 & 10 \\
Human threat when walking in the night & 2 & 6.7 \\
\hline Total & 30 & 100 \\
\hline
\end{tabular}

Table 2: Crop lost by elephants in some African Countries (Hoare, 1999 cited in FAO, 2009)

\begin{tabular}{llll}
\hline country & Zone & Year of study & \% lost \\
\hline Gabon & Gamba & 1996 & 0.75 \\
& & 1998 & $0.3-6.2$ \\
Ghana & Red Volta & 1996 & 8.6 \\
Malawi & Kasungu & 1981 & 6.3 \\
& Liwonde & 1997 & 8.8 \\
Mozambique & Maputo & 1996 & 10.2 \\
Uganda & Kibale & 1996 & 21 \\
Zimbabwe & Binga & 1994 & 11.7 \\
\hline & Sengwa & 5.4 \\
\hline
\end{tabular}




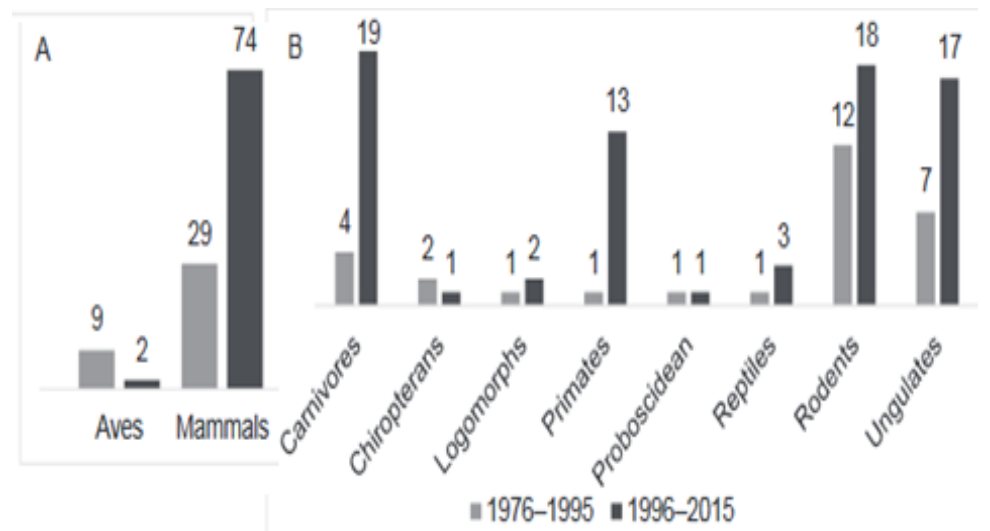

Fig1: Number of species involved in HWC from 1976-1995 and from 1996-2015 (Source Anand and Radhakrishna, 2017)

Conservation efforts: Human wildlife conflict is hindering the implementation of conservation initiatives (Gusset at al., 2009; Osborn and Hill (2005). According to Hill and Wallace, 2012, human primate conflict affects conservation efforts in Africa. Because of this conflict human beings have a negative impact on the conservation of wildlife in the wild since the people has disliked the species because of property loss that contributes for food insecurity and poverty. Human wildlife conflict has become more frequent, severe and serious obstacles to conservation efforts in Africa (Eniang et al., 2011). Conflict between human and wildlife is one of the most widespread and intractable issues facing conservation biologist today (Dickman, 2010). Human wildlife conflicthinders the conservation of animals in the natural habitats and poses the greatest challenges to the persistence and survival of wildlife (Hoffman and Riain, 2012; Dickman (2010).

Conclusions: Wildlife in developing countries causes considerable impacts on crops and livestock's production. The transformation of forests, savannah and other ecosystems into agricultural fields by human beings are some of the major contributors for humanwildlife conflicts.Crop-riding by wild animals is one of the major causes for the conflict. Crop-raiding undermines food security and tolerance of wildlife within neighboring human communities. Human wildlife conflict has negative impacts on wildlife conservation in the natural habitats and poses the greatest challenges to the persistence and survival of wildlife.

Acknowledgments: We would like to acknowledges our institutes Jimma University College of Agriculture and Veterinary Medicine and Wolkite University, College of Natural and Computational Science for the existing internet facilities to download relevant scientific published articles and reports from various databases, Google scholar, TEEAL, Google web based search and others to conduct this review paper on the impacts of human-wildlife conflict in developing countries.

\section{REFERENCES}

Acharya, KP; Paudel, PK; Janwali, SR; Neupane, PR; Kohl, M (2017). Can forest fragmentation and configuration work as indicators of human-wildlife conflict? Evidences from human-death and injury by wildlife attacks in Nepal. Ecological Indicators. 80: 74-83.

Anand, S; Radhakrishna, S (2017). Investigating trends in human-wildlife conflict: is conflict escalation real or imagined? Journal of AsiaPacific Biodiversity. 10:154-161.

Conover, M (2002). Resolving Human Wildlife Conflicts: The Science of Wildlife Damage Management. Lewis Publisher, CRC Press LLC.

Datta-Roy, A; Nimes, V; Williams, AC (2009). Participatory Elephant Monitoring in South Garo Hills: Efficacy and Utility in Human-Animal Conflict Scenario, Tropical Ecology, 50 (1): 163171.

Dickman, AJ (2010). Complexities of Conflict: The Importance of Considering Social Factors for Effectively Resolving Human-Wildlife Conflict. Animal Conservation. 13: 458-456.

Eniang, EA; Ijeomah, HM; Okeyoyin, G; Uwatt, AE (2011). Assessment of Human-Wildlife Conflicts in Filinga Range of Gashaka Gumti National Park, Nigeria, Publication of Nasarawa State University, Keffi. 7(1): 15-35.

Everard, M; Khandal, D; Sahy, YK. (2017). Ecosystem service enhancement for the alleviation of wildlife-human conflict in the Aravalli Hills, Rajastan, India. Ecosystem services. 24: 213- 222. 
Fenta, MM (2014) Human-Wildlife Conflicts: Case Study in Wondo Genet District, Southern Ethiopia.Agriculture, Forestry and Fisheries. 3(5): 352-362

Food and Agriculture Organization of the United Nations (FAO) 2009. Human-Wildlife Conflict in Africa, Causes, Consequences and Management Strategies.

Fourie, NH;Turner, TR; Brown, JL; Pampush, JD; Lorenz, JG; Bernstein, RM (2015). Variation in Vervet (Chlorocebus aethiops) hair cortisol concentrations reflects ecological disturbance by humans, Primates, http://www.ncbi.nlm.nih.gov/pubmed/26318176.

Gandiwa, E; Gandiwa, P; Muboko, N (2012). Living with Wildlife and Associated Conflicts in a Contested Area within the Northern Gonarezhou National Park, Zimbabwe, J. Sustainable Development in Africa. 14 (6): 252-260.

Gandiwa, E; Heitkönig, LMA; Lokhorst, AM; Prins, HHT; Leeuwis, C (2013). CAMPFIRE and Human-Wildlife Conflicts in Local Communities Bordering Northern Gonarezhou National Park, Zimbabwe. Ecology and Society. 18 (4), 4.

Gusset, M; Swarner,MJ; Mponwane,L; Keletile,K; McNut, JW (2009).Human-Wildlife Conflict in Northern Botswana: Livestock Predation by Endangered Africa Wild dog Lycaon pictus and other Carnivores, Oryx.43: 67-72.

Hill, CM (2005). People, Crops and Primates: a Conflict of Interest, Department of Anthropology, Oxford Books University, Uk.

Hill, CM; Wallace, GE (2012). Crop Protection and Conflict mitigation: reducing the cost of living alongside non-human primates, Biodiversity Conservation. 21: 2569-2587.

Hill, CM (1998). Conflicting Attitudes towards Elephants around the Budungo Forest Reserve. Environ. Conser. 25: 244-250.

Hockings, K; Humle, T (2009). Best Practicies Guidelines for the Prevention and Mitigations of Conflict between Humans and Great Apes, Occasional Paper of the IUCN Species Survival Commissions No 37.
Hoffman, TS; O'Riain, JS (2012). Monkey Management: Using Spatial Ecology to Understand the Extent and Severity of HumanBaboon Conflict in the Cape Peninsula, South Africa. Ecology and Society. 17 (3): 13.

Kansky, R., Knight, AT (2014). Key factors driving attitudes towards large mammals in conflict with humans. Biological Conservation. 79:93-105.

Kate, K (2012). Possible Strategies/ Practices in Reducing Wild animals (Primate) Crop raids in unprotected areas in Hoima District, Conducted in two Sub-Counties in Hoima District, A report to the PCLG-Uganda.

Kissui, B (2008). Livestock predation by lions, leopards, spotted hyenas and their vulnerability to retaliatory killing in the Maasai Steppe, Tanzania. Animal Conservation. 11 (5): 422-432.

Knight, J (ed.) (2000). Natural Enemies, PeopleWildlife Conflicts in Anthropological Perspective (European Association of Social Anthropologist), Routledge, London, Great Britain.

Mackenzie, CA; Ahabyona, P (2012). Elephants in their garden: financial and social costs of crop raiding. Ecological Economics. 75: 72-82.

Marchal, V; Hill, C (2009). Primate Crop-raiding: A Study of Local Perceptions in Four Villages in North Sumatra, Indonesia. Primate Conservation. 24: 107-116.

Mishra, DK; Rathore, SS; Pandey, D (2014). HumanWildlife Conflict and Wildlife Watershed Management, International Journal of Bioassays. 3(08): 3210-3213.

Mishra, DK; Rathore, SS; Pandey, D (2014). HumanWildlife Conflict and Wildlife Watershed Management. International Journal of Bioassays. 3 (8), ISSN: 2278 -778X.

Mojo, D; Rothschuh, J; Alebachew, M (2014). Farmers Perceptions of the Impacts of Human Wildlife Conflict on their Livelihood and Natural Resources Management Efforts in Cheha Woreda of Gurage Zone, Ethiopia. Human-wildlife interactions. 8 (1): 67-77.

Mwamidi, DM; Mwasi, SM; Nunow, AA (2012). The use of Indigenous Knowledge in Minimizing Human-wildlife conflict: The case of Taita 
Community, Kenya. Inter. J. Current Res. 4 (2): 026-030.

Ogra, M; Badola, R (2008). Compensating HumanWildlife Conflict in Protected Area Communities: Ground-Level Perspectives from Uttarakhand, India, Hum Ecol. 36: 717-729.

Osborn, FV; Hill, CM (2005). Techniques to Reduce Crop Loss: Human and Technical Dimensions in Africa. In People and Wildlife: Conflict or Coexistence? (Woodroffe, RS; Thirgood; Rabinowitz, A (eds) pp.72-85, Cambridge University Press, Cambridge, UK.

Regmi, GR; Nekarisi, Kai; Kandel, K; Nijman, V (2013). Crop-raiding Macaques: Predictions, Patterns and Perceptions from Langtang National Park, Nepal, Endangered Species Research. 20: 217-226.
Singh, M; Cheyne, SM; Smith, DAE (2018). How conspecific primates use their habitats: Surviving in an anthropogenically-disturbed forest in Central Kalimantan, Indonesia. Ecological Indicators. 87: 167-177.

Torres, DF; Oliveeira, ES; Nobrega Alves, RM (2018). Understanding human-wildlife conflicts and their implications. Ethnozoology. pp. 421-445.

Wong, WM; Leader-Williams, N; Linkie, M (2015). Managing Human-Sun Bear Conflict in Sumatran Agroforest Systems, Hum Ecol. 43: 255-266.

Woodroffe, R; Thirgood, S; Rabinowitz, A (2005). People and Wildlife, conflict or co-existence? Conservation Biology (No.9).

Yihune, M; Bekele, A; Tefera, Z (2009). HumanWildlife Conflict and around the Simien Mountains National Park, Ethiopia. SINET: Ethiopia. J. Sci. 32 (1): 57-64. 